\title{
PREVALENCIA DE ANTICORPOS ANTI-Leptospira spp. E ASPECTOS EPIDEMIOLÓGICOS DA INFECÇÃO EM BOVINOS DO ESTADO DE GOIÁS
}

\author{
Alberto Elias Marques, ${ }^{1}$ William Vilela Rocha, ${ }^{2}$ Wilia Marta Elsner Diederichsen de Brito, ${ }^{3}$ \\ Maria Clorinda Soares Fioravanti, ${ }^{4}$ Ivonete Maria Parreira ${ }^{5}$ e Valéria de Sá Jayme ${ }^{4}$ \\ 1. Departamento de Medicina Veterinária, Escola de Veterinária, UFG. E-mail: albertovetufg@gmail.com \\ 2. Agrodefesa, GO \\ 3. Professora doutora do Instituto de Patologia Tropical e Saúde Pública, UFG \\ 4. Professora doutora, Departamento de Medicina Veterinária, Escola de Veterinária, UFG \\ 5. Programa de Pós-Graduação em Ciência Animal, Escola de Veterinária, UFG.
}

RESUMO

O presente trabalho visou determinar a prevalência de soroaglutininas anti-Leptospira spp., determinar sua distribuição regional e avaliar os principais fatores associados à enfermidade em bovinos do Estado de Goiás. Realizou-se o estudo utilizandose 4.571 amostras colhidas em 715 propriedades de 213 dos 246 municípios do Estado de Goiás, as quais foram analisadas pela técnica de soroaglutinação microscópica (SAM). Detectaram-se $62,2 \%$ de amostras positivas para pelo menos um dos dezesseis sorovares testados, com predominância de coaglutinações $(40,24 \%)$, seguidas pelos sorovares Wolffi (14,53\%), Hardjo (12,70\%),
Grippotyphosa (10,55\%) e Shermani (6,55\%). A prevalência de anticorpos anti-Leptospira spp. foi associada aos seguintes fatores: estrato de produção, sendo mais prevalente no estrato de produção predominantemente de bovinos para corte; prática de inseminação artificial; raça dos animais; presença de ovinos e caprinos; presença de capivaras; compra de reprodutores em exposições e de outras propriedades; aluguel de pastos em alguma época do ano; presença de piquete maternidade e ocorrência de abortos. Concluiu-se que a infecção por Leptospira spp. é endêmica no Estado de Goiás.

PALAVRAS-CHAVES: Aglutininas anti-Leptospira spp., bovinos, Goiás, soroaglutinação microscópica, soroepidemiologia.

\section{ABSTRACT}

\section{PREVALENCE OF ANTI- Leptospira spp. ANTIBODIES AND EPIDEMIOLOGICAL ASPECTS OF THE} INFECTION IN CATTLE OF GOIAS/BRAZIL

This study aimed to determine the prevalence of antibodies against Leptospira spp. and their regional distribution, and evaluate the main risk factors associated to the disease in cattle in the State of Goias, Brazil. The study was carried out using 4571 samples taken from 715 properties of 213 municipalities in the state of Goias. The samples were analysed by the microagglutination test (MAT). $62.2 \%$ of the samples were positive for at least one of the 16 serovars tested, with major prevalence of co-agglutination (40.24\%), followed by serovars wolffi (14.53\%), hardjo (12.70\%), grippotyphosa (10.55\%) and shermani $(6.55 \%)$. The prevalence of anti-Leptospira spp. antibodies was associated to the following factors: stratum of production, with a greater prevalence in stractum of beef cattle production; practice of artificial insemination; cattle breed; presence of sheep and goats; presence of capybaras; purchase of reproducers in exhibitions and from other properties; pasture rent at any time of year; presence of maternity paddock, and occurrence of abortions. It was concluded that leptospiral infection is endemic in Goias State.

KEYWORDS: Cattle, Goias, Leptospira spp., microagglutination test, seroepidemiology. 


\section{INTRODUÇÃO}

O Brasil possui o segundo maior rebanho bovino do mundo, com um efetivo aproximado de 162 milhões de animais, sendo, pois, inquestionável a aptidão nacional para a exploração pecuária. O Estado de Goiás ocupa o terceiro lugar no País, com cerca de 20.646 milhões de cabeças, constituindo-se no terceiro rebanho de corte e no segundo leiteiro em termos nacionais (IBGE, 2008). Portanto, a pecuária bovina representa no Estado uma atividade produtiva de caráter permanente e consolidado, com grande representatividade econômica. Essa produção, bastante significativa em termos quantitativos, convive, entretanto, com inúmeros entraves, a exemplo do que ocorre no País, uma vez que os valores médios de produção e produtividade dos rebanhos nacionais situam-se em patamares desfavoráveis quando comparados aos ocorrentes em outros países.

Diversos são os fatores que contribuem para esse quadro, o que aponta para a necessidade de mudanças que visem à maior produtividade e ao melhor desempenho dos criatórios. Para incrementar os patamares de produção, consideráveis modificações na forma de exploração vêm sendo desenvolvidas, alterando-se, assim, diversas práticas e manejos (PFIZER, 2000).

Nesse cenário, mudanças como maior movimentação de animais, introdução crescente de novos indivíduos para melhoria zootécnica, novas práticas de reprodução, como inseminação artificial, e aumento de confinamentos para a engorda precoce, dentre outras, embora fundamentais para uma maior produtividade, podem propiciar, quando não desenvolvidas com cuidados sanitários, condições epidemiológicas favoráveis à introdução, manutenção e disseminação de agentes de doenças transmissíveis.

Dentre essas últimas, as enfermidades que envolvem a esfera reprodutiva, responsáveis pela ocorrência de abortos, infertilidade, esterilidade ou nascimento de produtos debilitados, constituem condição de especial interferência no processo produtivo, aspecto que se agrava quando o agente envolvido, além de afetar um amplo espectro de espécies animais susceptíveis, atingir também o ser humano. Este é o caso da leptospirose, enfermidade responsável por grandes perdas econômicas na produção de bovinos, decorren- tes de abortos, nascimento de bezerros debilitados e infertilidade (LILENBAUM, 1996).

De acordo com ARAÚJO et al. (2005), no Brasil a leptospirose bovina, além de não ser doença de notificação compulsória, não está submetida ao combate organizado por órgãos e entidades públicas ou privadas de sanidade animal, o que dificulta conhecer a verdadeira extensão das infecções por Leptospira spp. nos rebanhos bovinos em qualquer região do País.

A determinação da taxa de prevalência é essencial para a quantificação do problema em termos populacionais, servindo de base para caracterizações epidemiológicas, uma vez que o diagnóstico amplo, rápido e preciso das enfermidades é fundamental para elaboração de alternativas viáveis de intervenção. Destaca-se que, segundo LILENBAUM (1996), a profilaxia e o controle das leptospiroses bovinas dependem, primariamente, de um diagnóstico em que se procure identificar na propriedade qual sorovar predominante e, consequentemente, quais mecanismos de transmissão presentes.

Dentre outros, FAVERO et al. (2001) analisaram exames de soroaglutinação microscópica (SAM) efetuados no período de 1984 a 1997 em 31.325 bovinos de 1920 propriedades distribuídas em 540 municípios de 21 estados do Brasil. Os resultados revelaram que $84,10 \%$ das propriedades e $94,18 \%$ de municípios apresentavam pelo menos uma amostra positiva. A média de animais reagentes entre os estados foi de $49,51 \%$, sendo os sorovares mais prevalentes, exceto as coaglutinações, Hardjo, Wolffi e Grippotyphosa.

Estudos já desenvolvidos em Goiás comprovaram a existência da infecção em rebanhos estaduais e indicaram a necessidade de estudos que apontem a real magnitude do problema, já que os dados locais referentes à enfermidade são relativamente restritos e esparsamente relatados, o que pode estar relacionado à relativa dificuldade de diagnóstico laboratorial, dada a diversidade de manifestações clínicas e complexidade etiológica.

No Estado, levantamento sorológico realizado isoladamente na espécie bovina registrou prevalência média de $20,57 \%$, com predominância dos sorotipos Wolffi (50\%), Pomona (38,4\%), Grippotyphosa e Icterohaemorrhagiae $(5,8 \%)$, e títulos variando de 1:400 a 1:1600 (JARDIM, 1978), não tendo sido testado na época o sorovar Hardjo, que só foi adicionado às ba- 
terias de teste nacionais na década de 1980. JULIANO (1999) observou prevalência de $81,90 \%$ de animais reagentes entre 426 amostras de hemossoro bovino, provenientes de vacas em lactação na microrregião de Goiânia, em Goiás, que abrange dezessete municípios, sendo os principais sorovares encontrados Wolffi $(36,10 \%)$, Icterohaemorrhagiae $(20,50 \%)$, Hardjo $(5,20 \%)$ e Tarassovi $(4,90 \%)$.

Já por FAVERO et al. (2001), foram analisadas 1.406 amostras de soro de bovinos de 28 municípios de Goiás, coletadas no período de 1984 a 1997, sendo 487 $(34,6 \%)$ positivas na SAM. A porcentagem de municípios positivos foi de $100 \%$ e a de propriedades positivas foi de 97,8\%, sendo o sorovar Hardjo responsável por $63,7 \%$ e o sorovar Wolffi por $13 \%$ das reações positivas.

Também em Goiás, CAMPOS JR. et al. (2006) analisaram 140 amostras de reprodutores bovinos referentes a sessenta propriedades da Microrregião de Goiânia, tendo sido encontrados $74,28 \%$ de amostras reagentes e títulos com variação de diluição de 1:100 a 1:800. Os sorovares mais detectados foram Wolffi (19,23\%); Hardjo (15,38\%); Djasiman E Grippotyphosa (5,76\%); Shermani (4,80\%); Patoc (1,92\%); Andamana, Castellonis, Copenhageni, Hebdomadis, Sentot e Tarassovi $(0,96 \%)$. Os autores concluíram que o agente estaria endemicamente distribuído na região, não tendo verificado relação entre a positividade e a aptidão do rebanho ou a ocorrência de abortos.

Considerando a escassez de informações epidemiológicas sobre a leptospirose bovina em Goiás, constituíram-se objetivos deste trabalho investigar a prevalência de anticorpos anti-Leptospira spp. no re- banho bovino, contribuindo para o monitoramento da saúde animal no Estado, de forma a embasar o controle da enfermidade e a minimizar as perdas decorrentes, aspecto essencial quando se considera que a exploração pecuária representa uma das principais atividades econômicas regionais.

\section{MATERIAL E MÉTODOS}

O Estado de Goiás possui 246 municípios (IBGE, 2008) e, para efeito do presente estudo, foi dividido em três regiões, conforme ROCHA (2003), de acordo com a produção predominante em cada uma. A região um foi composta pelas Regiões Norte e Nordeste, com aptidão predominante de corte; a região dois, pelas Regiões Sul e Sudeste, com aptidão predominante de leite; e a região três compreendeu as Regiões Sudoeste e Centro, com aptidão predominante mista.

Foram coletadas, em paralelo às ações do Programa Nacional de Controle e Erradicação da Brucelose e Tuberculose Bovina (PNCEBT), no ano de 2002, 4.571 amostras de soro de bovinos de 715 propriedades integrantes de 213 dos 246 municípios do Estado de Goiás. Empregou-se, para o diagnóstico sorológico, a técnica de soroaglutinação microscópica (SAM), que é o método de referência para detecção de anticorpos anti-Leptospira spp. (OIE, 1992), tendo sido utilizada uma coleção de dezesseis sorovares de Leptospira spp. (Quadro 1).

A metodologia e interpretação adotadas foram aquelas descritas no Manual of Standars for Diagnostics Tests and Vaccines (OIE, 1992).

QUADRO 1. Antígenos empregados na técnica de soroaglutinação microscópica (SAM), segundo código, sorogrupo e sorovar, mantidos pelo Laboratório de Diagnóstico de Leptospirose da Escola de Veterinária, UFG.

\begin{tabular}{cccccc}
\hline Código & Sorogrupo & Sorovar & Código & Sorogrupo & Sorovar \\
\hline $1-\mathrm{A}$ & Australis & Australis & $10-\mathrm{B}$ & Icterohaemorrhagiae & Icterohaemorrhagiae \\
$1-\mathrm{B}$ & Australis & Bratislava & 13 & Pomona & Pomona \\
$2-\mathrm{A}$ & Autumnalis & Autumnalis & 14 & Pyrogenes & Pyrogenes \\
3 & Ballum & Castellonis & $15-\mathrm{A}$ & Sejroe & Hardjo \\
5 & Canicola & Canicola & $15-\mathrm{B}$ & Sejroe & Wolffi \\
8 & Grippotyphosa & Grippothyphosa & 16 & Shermani & Shermani \\
9 & Hebdomadis & Hebdomadis & 17 & Tarassovi & Tarassovi \\
$10-\mathrm{A}$ & Icterohaemorragiae & Copenhageni & St & Djasiman & Sentot \\
\hline
\end{tabular}


O sorovar considerado como provável causador da infecção foi o que apresentou maior título. $\mathrm{Na}$ eventualidade do maior título ser apresentado para dois ou mais sorovares, a amostra foi enquadrada como coaglutinação.

Juntamente com a coleta de amostras de soro, foi aplicado questionário fechado, elaborado com base em THRUSFIELD (2004), para a determinação dos fatores associados à leptospirose bovina em todas as propriedades integrantes do estudo.

\section{RESULTADOS E DISCUSSÃO}

Das 4.571 amostras, $2.843(62,20 \%)$ foram positivas para pelo menos um sorovar testado, com título mínimo de 1:100. A prevalência estadual por sorovar está discriminada na Tabela 1, podendo-se verificar a elevada ocorrência de coaglutinações $(40,24 \%)$ e a predominância de resposta ao sorovares Wolffi e Hardjo.

TABELA 1. Prevalência de anticorpos anti-Leptospira spp. no teste de SAM em 4.571 amostras de soro bovino de 715 proriedades e 213 municípios, por sorovar, Estado de Goiás

\begin{tabular}{lcc}
\hline \multicolumn{1}{c}{ Sorovar } & Positivas & \% \\
\hline Coaglutinação & 1.144 & 40,24 \\
Wolffi & 413 & 14,53 \\
Hardjo & 361 & 12,70 \\
Grippotyphosa & 300 & 10,55 \\
Shermani & 192 & 6,75 \\
Pomona & 81 & 2,85 \\
Castellonis & 76 & 2,67 \\
Pyrogenes & 67 & 2,36 \\
Hebdomadis & 57 & 2,00 \\
Australis & 41 & 1,44 \\
Tarassovi & 36 & 1,27 \\
Canicola & 25 & 0,88 \\
Bratislava & 19 & 0,67 \\
Copenhageni & 13 & 0,46 \\
Icterohaemorragiae & 11 & 0,39 \\
Sentot & 4 & 0,14 \\
Autumnalis & 2 & 0,07 \\
$\quad$ Total & 2.843 & $100 \%$ \\
\hline
\end{tabular}

Ci. Anim. Bras., Goiânia, v. 11, n. 3, p. 607-617, jul./set. 2010
Constituiu-se o estrato um de 1.314 amostras, provenientes de 209 propriedades de 58 municípios. Dessas amostras, $946(71,99 \%)$ foram positivas para pelo menos um sorovar testado. Amostraram-se no estrato dois 1.542 animais de 241 propriedades de 78 municípios, das quais 834 (54,09\%) foram positivas. $\mathrm{O}$ estrato três foi constituído por 1.715 amostras, oriundas de 266 propriedades de 77 municípios, sendo detectadas $1.063(61,98 \%)$ amostras positivas.

As propriedades com pelo menos uma amostra positiva no teste de SAM foram consideradas positivas, assim como os municípios com pelo menos uma amostra positiva foram igualmente considerados positivos.

Das 715 propriedades amostradas, $688(96,23 \%)$ tiveram pelo menos uma amostra positiva, comprovando a endemicidade da infecção em Goiás. No estrato um, composto de 209 propriedades, como já registrado, $208(99,52 \%)$ foram positivas. No estrato dois, composto de 241 propriedades, $228(94,61 \%)$ foram positivas. O estrato três foi composto de 266 propriedades, das quais $252(95,11 \%)$ foram positivas.

Dos 213 municípios integrantes deste estudo, somente o município de Vila Boa, integrante do estrato três, não apresentou nenhuma amostra positiva, totalizando $99,53 \%$ de positividade entre os municípios do Estado e $100 \%$ de positividade para os municípios dos estratos um e dois, e 98,70 \% de positividade entre os municípios do estrato três.

A prevalência por sorovar nos estratos um, dois e três, em ordem decrescente, está discriminada nas Tabelas 2, 3 e 4, respectivamente, registrando-se que para os sorovares Sentot e Autumnalis não foram detectadas amostras positivas no estrato um, bem como para o sorovar Autumnalis no estrato três.

A porcentagem de reagentes no presente estudo foi superior à encontrada por FAVERO et al. (2001), LANGONI et al. (2001), MINEIRO (2003), AGUIAR et al. (2006) e LAGE et al. (2007), que analisaram diferentes regiões do Brasil. Foi também maior do que a relatada por JARDIM (1978), mas inferior às verificadas por JULIANO (1999) e CAMPOS JÚNIOR et al. (2006), que realizaram seus estudos enfocando a microrregião de Goiânia.

As coaglutinações, que ocorreram em 1.144 $(40,24 \%)$ animais amostrados, sendo a coaglutinação entre sorovares Hardjo e Wolffi a mais frequente, seguida pela coaglutinação entre os sorovares Hardjo, Wolffi 
e Hebdomadis, podem ser explicadas, como apontado por JULIANO (1999) e BOLIN (2003), pela infecção concomitante de vários sorovares de Leptospira spp. ou por reações cruzadas entre sorovares de um mesmo sorogrupo.

TABELA 2. Prevalência de anticorpos anti-Leptospira spp., por sorovar, no estrato amostral um, de produção predominantemente de corte, Estado de Goiás

\begin{tabular}{lcc}
\hline \multicolumn{1}{c}{ Estrato 1 } & Positivas & $\%$ \\
\hline Coaglutinação & 421 & 44,50 \\
Wolffi & 143 & 15,12 \\
Hardjo & 101 & 10,68 \\
Grippotyphosa & 84 & 8,88 \\
Shermani & 57 & 6,03 \\
Pyrogenes & 29 & 3,07 \\
Castellonis & 28 & 2,96 \\
Australis & 14 & 1,48 \\
Pomona & 13 & 1,37 \\
Tarassovi & 13 & 1,37 \\
Hebdomadis & 12 & 1,27 \\
Canicola & 12 & 1,27 \\
Bratislava & 9 & 0,95 \\
Copenhageni & 5 & 0,53 \\
Icterohaemorragiae & 4 & 0,42 \\
\multicolumn{1}{c}{ Total } & 945 & $100 \%$ \\
\hline
\end{tabular}

TABELA 3. Prevalência de anticorpos anti-Leptospira spp., por sorovar, no estrato amostral dois, de produção predominantemente de leite, Estado de Goiás

\begin{tabular}{lcc}
\hline \multicolumn{1}{c}{ Estrato 2} & Positivas & $\%$ \\
\hline Coalglutinação & 307 & 36,81 \\
Hardjo & 144 & 17,27 \\
Wolffi & 119 & 14,27 \\
Grippotyphosa & 82 & 9,83 \\
Shermani & 61 & 7,31 \\
Pomona & 29 & 3,48 \\
Hebdomadis & 21 & 2,52 \\
Australis & 16 & 1,92 \\
Pyrogenes & 16 & 1,92 \\
Castellonis & 14 & 1,68 \\
Tarassovi & 10 & 1,20 \\
Copenhageni & 6 & 0,72 \\
Bratislava & 4 & 0,48 \\
Autumnalis & 2 & 0,24 \\
Canicola & 1 & 0,12 \\
Icterohaemorragiae & 1 & 0,12 \\
Sentot & 1 & 0,12 \\
\multicolumn{1}{c}{ Total } & 834 & $100 \%$ \\
\hline
\end{tabular}

TABELA 4. Prevalência de anticorpos anti-Leptospira spp., por sorovar, no estrato amostral três, de produção predominantemente mista, Estado de Goiás

\begin{tabular}{lcc}
\hline Estrato 3 & Positivas & $\%$ \\
\hline Coalgutinação & 416 & 39,13 \\
Wolffi & 151 & 14,21 \\
Hardjo & 116 & 10,91 \\
Grippotyphosa & 134 & 12,61 \\
Shermani & 75 & 7,06 \\
Pomona & 39 & 3,67 \\
Castellonis & 34 & 3,20 \\
Canicola & 34 & 3,20 \\
Hebdomadis & 24 & 2,26 \\
Pyrogenes & 22 & 2,07 \\
Tarassovi & 13 & 1,22 \\
Australis & 11 & 1,03 \\
Bratislava & 6 & 0,56 \\
Copenhageni & 6 & 0,56 \\
Icterohaemorragiae & 6 & 0,56 \\
Sentot & 3 & 0,28 \\
$\quad$ Total & 1.090 & $100 \%$ \\
\hline
\end{tabular}

A observação de maiores prevalências para os sorovares Hardjo e Wolffi está em conformidade com a maioria dos inquéritos sorológicos realizados em bovinos em Goiás (JULIANO, 1999; FAVERO et al., 2001; CAMPOS JÚNIOR et al., 2006) e no Brasil (FAVERO et al., 2001; LANGONI et al., 2001; MINEIRO et al., 2003; ARAÚJO et al., 2005; AGUIAR et al., 2006; MAGAJEVSKI et al., 2007). Este resultado reveste-se de especial significado, uma vez que o sorovar Hardjo é considerado o mais difundido mundialmente e causador de grande impacto econômico na atividade pecuária, como consequência do abortamento, conforme registrado por LILEMBAUM (1996), (1997a) e GOMES (2008). Foram encontrados títulos para esse sorovar de até 1:3200 em alguns poucos animais, concordando com KIRKBRIDE (1990), que citou que títulos para o sorovar Hardjo em geral são baixos, sendo raramente superiores a 1:800.

A proximidade verificada nos valores de prevalência dos sorovares Hardjo e Wolffi provavelmente ocorreu por reação cruzada para os dois sorovares, pertencentes ao sorogrupo Sejroe, como afirmado por FAINE et al. (1999). CAMPOS JÚNIOR et al. 
(2006), que registraram prevalência de $74,28 \%$ entre bovinos reprodutores da microrregião de Goiânia, também detectaram como mais prevalentes os sorovares Wolffi $(19,23 \%)$ e Hardjo (15,38\%), seguidos pelos sorovares Djasiman, Grippotyphosa $(5,76 \%)$ e Shermani $(4,80 \%)$, quadro semelhante ao observado no presente estudo.

Embora não se descarte a possibilidade de infecção pelo sorovar Wolffi, deve ser considerada a afirmação de ARAÚJO et al. (2005), de que até 2005 não foram encontradas publicações científicas e/ou técnicas com registros do isolamento de Wolffi em bovinos nos casos clínicos sugestivos de leptospirose. Tal condição reforça a consideração de que a prevalência encontrada para o sorovar Wolffi no presente estudo se trate de reação cruzada com o sorovar Hardjo, o que por outro lado amplia a importância deste último na pecuária local.

A prevalência encontrada para o sorovar Grippotyphosa foi superior à relatada em outros inquéritos sorológicos em populações de bovinos (JARDIM, 1978; LANGONI et al., 2001; AGUIAR et al., 2006; CAMPOS JR. et al., 2006; MAGAJEVSKI et al., 2007). Como afirmado por LILENBAUM (1996), a ocorrência de infecções incidentais, causadas por sorovares que não são mantidos nos bovinos, como Australis, Bratislava, Butembo, Castellonis, Grippotyphosa, Copenhageni, Panama, Pyrogenes, Shermani, Andamana e Patoc, deve-se ao contágio indireto, pois animais mantidos a pasto têm acesso livre a lagoas, banhados e matas ciliares, onde existem animais silvestres e roedores que podem atuar como portadores e transmitirem estes sorovares para os bovinos.

Um resultado relevante aqui encontrado foi o da prevalência do sorovar Shermani no Estado (6,75\%) e entre os estratos (um - 6,03\%; dois - 7,31\%; três $-7,06 \%$ ). Como este sorovar, patogênico para a espécie bovina e demais espécies, não é um componente antigênico das vacinas comercializadas no Estado, a prevalência encontrada aponta para prejuízos causados por ele.

Avaliando-se os resultados de prevalência estadual e por estrato amostral constatou-se baixa prevalência de anticorpos de sorovares adaptados a roedores, como o Icterohaemorragiae e Copenhageni, ambos pertencentes ao sorogrupo Icterohaemorragiae, concordando com o observado por LANGONI et al.
(2001), em São Paulo, e CAMPOS JR. et al. (2006), em Goiás.

Diante dos resultados obtidos no presente estudo, pôde-se concluir que houve uma maior importância da transmissão entre bovinos portadores do agente patogênico, demonstrada pela maior prevalência dos sorovares Wolffi e Hardjo, este último adaptado à espécie bovina (ELLIS, 1984), em relação à transmissão da leptospirose por roedores.

A realização de um inquérito epidemiológico se mostrou necessária para correlacionar a prevalência de animais reagentes na SAM a diversas variáveis de aspecto sanitário, reprodutivo, produtivo, práticas de manejo e fatores ambientais.

A detecção de anticorpos anti-Leptospira spp. mostrou-se relacionada aos seguintes fatores: estrato de produção; prática de inseminação artificial; raça dos animais; presença de ovinos e caprinos; presença de capivaras; compra de reprodutores em exposições e de outras propriedades; aluguel de pastos em alguma época do ano; presença de piquete maternidade e ocorrência de abortos. Por outro lado, não foi constatada associação significativa com os seguintes fatores: tipo de criação praticada na propriedade; presença de equídeos, suínos, cães, gatos, cervídeos e outros animais silvestres; presença de outros animais; compra de reprodutores em feiras e/ou leilões; venda de reprodutores em exposições, feiras e/ou leilões, de comerciantes ou de outras propriedades; presença de pastos em comum com outras propriedades; assistência veterinária e vacinação contra brucelose, rinotraqueíte infecciosa bovina e diarreia viral bovina.

Avaliando-se, inicialmente, a questão dos três distintos estratos de produção, verificou-se que houve diferença significativa $(\mathrm{p}<0,001)$ para a prevalência dos títulos de anticorpos. O estrato um, de maior predominância de produção de bovinos para corte, apresentou a maior prevalência entre os três estratos, também com prevalência mais elevada de coaglutinações, seguidas pelos sorovares Wolffi, Hardjo e Grippotyphosa.

Ao se analisar os resultados registrados nas Tabelas 2, 3 e 4, nas quais foram expressas as prevalências por estrato amostral, verificou-se que a distribuição dos sorovares mais prevalentes foi muito semelhante entre os estratos e à prevalência geral do Estado, sendo igualmente maior no estrato um, de produção predominantemente de corte. 
Não foi constatada diferença significativa para a prevalência de aglutininas entre os tipos de criação extensiva, semiconfinamento e confinamento $(\mathrm{p}=0,170)$.

Comparando este resultado com os de CASTRO et al. (2008), em São Paulo, verificou-se sua semelhança, uma vez que os autores apontaram distribuição praticamente homogênea do sorovar Hardjo no Estado, de forma independente das diferentes condições de cada região, do tipo de exploração do rebanho e das práticas de reprodução. Tal quadro discordou do descrito por PRESCOTT et al. (1988), que apontaram os rebanhos de exploração de corte como mais suscetíveis a este sorovar do que os rebanhos leiteiros, condição possivelmente relacionada às diferenças de manejo.

Avaliando-se individualmente outras variáveis, constatou-se que houve diferença significativa $(p=0,023)$ entre a prevalência de animais sororreagentes no SAM e o emprego de inseminação artificial (IA), sinalizando que esta prática estaria relacionada com maior índice de infecção e aparecimento de casos de leptospirose, uma vez que os títulos detectados foram mais prevalentes entre os animais submetidos à IA. Tal observação pode estar relacionada com a afirmação de VASCONCELLOS (1997) sobre a condição já amplamente confirmada de transmissão de leptospirose por machos bovinos tanto pela monta natural como pela inseminação artificial, pelo fato de a uretra ser o canal comum para eliminação de sêmen e urina. Pelo afirmado, torna-se imperativo o controle da qualidade do sêmen, através do controle da leptospirose nos machos doadores. Avaliando esta técnica de manejo reprodutivo, JULIANO (1999) não encontrou diferença significativa para este fator na microrregião de Goiânia.

Em relação à raça, foi detectada diferença significativa $(p=0,00)$ entre as diferentes categorias de bovinos, sendo a resposta sorológica mais prevalente em raças europeias de corte, seguidas pelos zebuínos, mestiços, outras raças e europeias de leite, resultado concordante com o afirmado por PRESCOTT et al. (1988).

Quanto à presença de ovinos e caprinos, constatou-se maior prevalência entre os bovinos criados em propriedades onde havia presença destas espécies $(\mathrm{P}=0,001)$, tendo sido detectadas maiores prevalências de coaglutinações, seguidas pelos sorovares Hardjo e
Grippotyphosa, nas propriedades com a presença de tais espécies. Este quadro reforçou a susceptibilidade das espécies à infecção, relatada em pesquisas como as de LANGONI et al. (1995), que verificaram que 160 $(44,44 \%)$ das 360 amostras de soro de ovinos do Estado de São Paulo foram positivas no SAM, e a possível transmissão destas espécies para bovinos.

De forma distinta à esperada, a prevalência de títulos e a presença de equídeos $(\mathrm{p}=0,821)$, suínos $(p=0,912)$, caninos $(p=0,980)$, felinos $(p=0,711)$, cervídeos $(p=0,451)$ e outros animais silvestres $(p=0,211)$, como roedores, com exceção de capivaras, e outros animais não enquadrados nas categorias anteriores $(p=0,482)$, não foram significativas. Destaca-se que já foi comprovada a infecção por leptospiras nestas espécies (OLIVEIRA, 1988; SHIMABUKURO et al., 2003; LINHARES et al., 2005; RODRIGUES et al., 2007), o que tornaria possível a sua transmissão para bovinos, em caso de promiscuidade entre espécies dentro de uma propriedade.

No presente estudo, a prevalência estadual do sorovar Pomona, adaptado à espécie suína (VASCONCELLOS, 1997), mas responsável por casos de aborto e infertilidade em bovinos (MILLER \& TURK, 1994; GOMES, 2008), foi de 2,85\% (81 das 2843 amostras positivas), relativamente baixa, apesar de a presença de suínos ter sido verificada em 238 (33,29\%) das 715 propriedades amostradas. FAVERO et al. (2001) observaram maior prevalência do sorovar Icterohaemorragiae em relação ao sorovar Pomona em suínos de Goiás e destacaram que este achado sugere que a evolução da suinocultura nacional observada nos últimos anos deve ter modificado o perfil de infecção por leptospiras, na qual o sorovar Pomona, tradicionalmente mantido pelos próprios suínos, estaria sendo substituído pelo Icterohaemorragiae. Tal quadro reforça a necessidade de procedimentos destinados ao controle de roedores sinantrópicos como parte do manejo das criações de suínos.

Dentre os animais silvestres, a presença específica de capivaras mostrou-se significativa $(p=0,002)$, sendo as coaglutinações, seguidas pelos sorovares Hardjo, Wolffi e Grippotyphosa, mais prevalentes entre os animais de propriedades em que foi relatada a presença de tal espécie. BELLO et al. (1984) citaram que os roedores silvestres, principalmente as capivaras, são reservatórios de Leptospira spp. Os mesmos autores 
reportaram que estudos realizados na Venezuela demonstraram que anticorpos contra os sorovares Wolffi, Hebdomadis, Hardjo e Canicola já foram observados nesses animais. Vale destacar que CASTRO et al. (2008) afirmaram que cervídeos, capivaras e outras espécies silvestres atuam como reservatórios de Leptospira spp. para os rebanhos bovinos ao encontrarem hábitat satisfatório.

A introdução de reprodutores mostrou-se significativa $(\mathrm{P}=0,049)$ para a prevalência de aglutininas anti-Leptospira spp., sendo a prevalência notadamente maior entre as propriedades onde foi relatada compra de reprodutores em exposições $(p=0,019)$ e de outras propriedades $(\mathrm{p}=0,00)$. Este resultado demonstra a possível aquisição de animais sem adoção de cuidados fundamentais, como exames de rotina, realização de quarentena e não vacinação, dentre outros.

Já quanto às práticas de venda de reprodutores, não foi observada diferença significativa relacionada $(\mathrm{p}=0,725)$. Destaca-se aqui que, de acordo com GUIMARÃES et al. (1982/83), LILENBAUM (1996) e VASCONCELLOS (1997), bovinos infectados usualmente eliminam leptospiras na urina por tempo prolongado, o que determina a contaminação de outros indivíduos e do ambiente. Assim, a venda de animais portadores assintomáticos para outras propriedades ofereceria grande risco de introdução do agente em uma propriedade livre deste, como demonstrado pela citada associação entre a compra de animais em exposições e de outras propriedades e a prevalência da leptospirose bovina.

Já quanto às práticas de aluguel de pastos em alguma época do ano, verificou-se a importância desta atividade com relação à positividade sorológica dos rebanhos amostrados, uma vez que foi verificada diferença significativa $(p=0,001)$. Tal resultado era esperado, pois o risco de introdução da leptospirose em um rebanho livre da enfermidade pela prática de aluguel de áreas para o pastejo de outros rebanhos é grande, caso o rebanho introduzido na área alugada esteja eliminando o agente na urina.

Por outro lado, a presença de pastos em comum com outras propriedades não demonstrou ser um dos fatores determinantes da presença de casos de leptospirose, não havendo diferença significativa $(p=0,05)$ para este fator. Entretanto, mesmo com este resultado, deve-se considerar, como registrado, a utilização de pastos em comum com outras propriedades como potencial fator de risco.

Uma observação importante foi a da maior prevalência sorológica entre os animais em cujas propriedades havia piquete separado para fêmeas na fase de parto ou pós-parto, havendo diferença significativa $(\mathrm{p}=0,00)$ para este fator. Tal observação pode ser justificada pela maior umidade do solo destes piquetes, resultante do acúmulo de grande quantidade de urina, via de eliminação de leptospiras, tornando maior o risco de infecção das fêmeas e bezerros neste ambiente. Associam-se a esta condição a maior concentração de animais no espaço desse tipo de piquete e o contato com eventuais produtos de abortos, ambos fatores de risco para a transmissão do agente.

A assistência veterinária não demonstrou ser um dos fatores determinantes de prevalência nas propriedades amostradas, não havendo diferença significativa $(\mathrm{p}=0,101)$ para este fator.

A observação de aborto na propriedade nos doze meses que antecederam a coleta das amostras, que se mostrou significativa $(\mathrm{p}=0,002)$, foi feita pelos proprietários de $67(9,37 \%)$ das 715 propriedades amostradas. Dos 2.830 animais com resultados positivos na SAM e com informações sobre o histórico de abortos, em $40(1,41 \%)$ foi registrado aborto nos doze meses que antecederam a coleta da amostra. Por outro lado, dos 1.717 animais com resultados negativos na SAM, sete $(0,004 \%)$ tinham histórico de aborto. Deve ser considerada, como relatado por BOLIN (2003), a possibilidade da ocorrência de abortos sem títulos de anticorpos detectáveis no exame de SAM, especialmente para o sorovar Hardjo, sendo que, frequentemente, na época do aborto os títulos de anticorpos podem estar bem baixos ou negativos nos hospedeiros de manutenção. Destaca-se que a observação de grande número de abortos, como afirmado por LILENBAUM (1996) e VASCONCELLOS (1997), acontece no caso da introdução recente do agente em um rebanho, o que gera grande número de casos que evoluem clinicamente. Com a cronicidade da infecção e o desenvolvimento de imunidade por grande parte dos animais de um rebanho, a ocorrência de abortos diminui, sendo mais dificilmente observada. Outro aspecto que deve ser considerado refere-se à possibilidade de não observação de abortos ocorridos nas propriedades, em espe- 
cial naquelas de corte, geralmente caracterizadas por grandes rebanhos criados de forma extensiva, o que dificulta seu monitoramento adequado.

Deve ser ainda considerada a ocorrência de outras causas de aborto que não por Leptospira spp., como nutrição, manejo e outras enfermidades que interferem na esfera reprodutiva, como brucelose, neosporose, IBR e BVD. Referendando tal afirmação, destacam-se os estudos de ROCHA (2003), que investigando a prevalência da brucelose bovina em Goiás registrou prevalência real ponderada de $19,61 \%(16,98 \%-22,24 \%)$, para as propriedades e $3,36 \%(3,02 \%-3,70 \%)$ para os animais, e os de SCHULZE (2008), que observou prevalência de anticorpos anti-Neospora caninum de $42,92 \%$ entre os 6.064 bovinos avaliados.

A vacinação para IBR, BVD e brucelose não mostrou associação com a prevalência da infecção, não havendo diferença significativa $(p>0,05)$ para estes fatores. Apenas um animal amostrado, positivo no SAM, já havia sido vacinado contra leptospirose. Pela ausência de informações sobre a vacinação dos animais amostrados contra leptospirose, assumiu-se que eles não eram vacinados contra a enfermidade e os resultados encontrados na SAM ocorreram por infecção natural, demonstrando a situação epidemiológica estadual.

A elevada prevalência de anticorpos antiLeptospira spp. observada no presente estudo pode ser justificada, dentre outros fatores, pela persistência do agente na natureza e pelo elevado potencial de infecção, assegurados pela diversidade de identidades sorológicas, pela multiplicidade de espécies hospedeiras e pelo relativo grau de sobrevivência das leptospiras patogênicas no ambiente.

A imunização é uma estratégia fundamental para a prevenção e controle da leptospirose em bovinos (ARAÚJO et al., 2005), destacando-se aqui a adequação do emprego de vacina composta pelos sorovares mais prevalentes no Estado, para aumento de sua eficiência. Ressalta-se, portanto, a importância da identificação das variantes sorológicas predominantes em uma região, uma vez que a imunidade é específica para ela, não havendo reação cruzada. Portanto, quando um ou mais sorovares infectam os animais é necessária a utilização de vacinas polivalentes, como afirmado por FAINE (1982), ELLIS (1984), LANGENEGGER (1990) e LILENBAUM (1996). Neste contexto, devem ser con- siderados ainda os prejuízos diretos ou indiretos relacionados a descartes de animais, custos com assistência veterinária, medicamentos e vacinas, o que demonstra a importância da adoção simultânea de importantes ações para o controle da enfermidade, ainda pouco desenvolvidas de forma efetiva pelos produtores.

Dentre elas, medidas apontadas por LILENBAUM \& SANTOS (1995), como a não introdução de animais nos rebanhos sem a realização de exame diagnóstico ou tratamento dos animais a serem introduzidos com diidroestreptomicina e o fortalecimento da imunidade de rebanho utilizando-se uma vacina que contenha, além do referido sorovar, outros sorovares presentes na região, assumem indiscutível relevância, diminuindo os impactos da enfermidade na espécie bovina.

Outro aspecto fundamental relativo aos resultados obtidos é o potencial impacto na saúde pública, ressaltando-se o caráter ocupacional da zoonose (BRASIL, 2005), em especial quando se considera o amplo leque de indivíduos que podem entrar em contato com bovinos infectados e que, porventura, estejam eliminando o agente. Assim, destaca-se o potencial risco de veterinários, proprietários, funcionários de propriedades e de abatedouros.

Considerando a complexidade do caráter multifatorial da leptospirose, maior conhecimento de sua epidemiologia reveste-se de significado para seu controle e consequente diminuição de seus graves impactos. Esta complexidade requer uma análise detalhada do ambiente, das espécies envolvidas e dos fatores de risco inerentes ao sistema de criação.

Diante do exposto, destaca-se a importância do aprimoramento dos sistemas de vigilância epidemiológica, visando à detecção precoce de focos, à investigação etiológica e à avaliação de eventuais modificações na estrutura epidemiológica da zoonose. Para tal, seriam fundamentais investimentos em infraestrutura, que permitissem atuação oportuna, adequada e na amplitude necessária, o incremento dos sistemas de informações, bem como capacitação técnica. Nesta última, incluem-se alguns componentes fundamentais, como capacitação clínica para suspeita da infecção/enfermidade, colheita e envio adequado de amostras e suporte laboratorial.

Finalizando, destaca-se que a educação em saúde, tanto no meio urbano quanto no rural, é fundamental para a implementação de medidas de profilaxia 
e controle, visando reduzir a magnitude da antropozoonose e de seus impactos sanitários, econômicos e sociais.

\section{CONCLUSÕES}

Concluiu-se que a infecção por Leptospira spp. é endêmica em bovinos de Goiás, com elevada prevalência de anticorpos anti-Leptospira spp. nos soros testados, tendo sido detectadas respostas sorológicas mais prevalentes para os sorovares Hardjo, Wolffi, Grippotyphosa e Shermani, indicativos de sua maior importância na infecção dos rebanhos amostrados

A observação de taxas expressivas de infecção pelo sorovar Hardjo, cuja principal forma de transmissão é de bovino para bovino, aponta para perdas econômicas relacionadas a abortos, natimortalidade e mastites, quadro presente em rebanhos do Estado.

Já a detecção de prevalência considerável de anticorpos contra os sorovares Grippotyphosa e Shermani indicou que os rebanhos bovinos estão sendo expostos ao agente pelo contato com animais silvestres, além de roedores, reservatórios destes sorovares.

A associação observada no presente estudo entre a ocorrência de infecção e a prática de inseminação artificial demonstrou a importância da certificação sanitária mais rigorosa do sêmen a ser utilizado neste procedimento.

As respostas sorológicas obtidas para os sorovares testados apontaram para a necessidade de composições mais apropriadas de vacinas para o rebanho estadual.

\section{REFERÊNCIAS}

AGUIAR, D. M.; GENNARI, S. M.; CAVALCANTE, G. T.; LABRUNA, M. B.; VASCONCELLOS, S. A.; RODRIGUES, A. A. R.; MORAES, Z. M.; CAMARGO, L. M. A. Seroprevalence of Leptospira spp. in cattle from Monte Negro municipality, western Amazon. Pesquisa Veterinária Brasileira, v. 26, n. 2, p. 102-104, 2006.

ARAÚJO, V. E. M.; NAVEDA, L. A. B.; SILVA, J. A.; CONTRERAS, R. L. Freqüência de aglutininas anti-Leptospira interrogans em soros sangüíneos de bovinos, em Minas Gerais, de 1980 a 2002. Arquivo Brasileiro de Medicina Veterinária e Zootecnia, v. 57, n. 4, p. 430-435, 2005.

BELLO, N. A.; LORD, V.; LASERNA, R. Enfermedades infecciosas que afectam el chiguire (Hidrochaeris hidrochaeris) en Venezuela. Revista Veterinaria Venezolana, v. 278, p. 32-44, 1984.
BOLIN, C. A. Diagnosis and control of bovine leptospirosis. In: WESTERN DAIRY MANAGEMENT CONFERENCE, 6., 2003, Reno. Proceedings... Reno, 2003. p. 155-160.

CAMPOS JÚNIOR, A. C. P.; FRENEAU, G. E.; JULIANO, R. S.; ACYPRESTE, C. S.; DIAS FILHO, F. C.; MARTINS, M. E. Prevalência de anticorpos antileptospira em machos bovinos na microrregião de Goiânia. Ciência Animal Brasileira, v. 7, n. 4, p. 439-446, out.-dez. 2006.

CASTRO, V.; AZEVEDO, S. S.; GOTTI, T. B.; BATISTA, C. S. A.; GENTILI, J.; MORAES, Z. M.; SOUZA, G. O.; VASCONCELLOS, S. A.; GENOVEZ, S. E. Soroprevalência da leptospirose em fêmeas bovinas em idade reprodutiva no Estado de São Paulo, Brasil. Arquivos do Instituto Biológico, v. 75, n. 1, p. 3-11, jan.mar. 2008 .

ELLIS, W. A. Bovine leptospirosis in the tropics: prevalence, pathogenesis and control. Preventive Veterinary Medicine, v. 2, p. 411-422, 1984.

FAINE, S. Guidelines for the control of leptospirosis. Geneva: World Health Organization, 1982. 171 p.

FAINE, S.; ADLER, B.; BOLIN, C. A.; PEROLAT, P. Leptospira and leptospirosis. 2. ed. Melbourne: MedSci, 1999. 272 p.

FAVERO, A. C. M.; PINHEIRO, S. R.; VASCONCELLOS, S. A.; MORAIS, Z. M.; FERREIRA, F.; FERREIRA NETO, J. S. Leptospirose bovina: variantes sorológicas predominantes em colheitas efetuadas no período de 1984 a 1997 em rebanhos de 21 estados do Brasil. Arquivos do Instituto Biológico, v. 68, n. 2, p. 29-35, jul.-dez. 2001.

GOMES, M. J. P. Gênero Leptospira spp. e leptospirose bovina. [online]. Disponível em: $<$ http://www.ufrgs.br/labacvet/pdf/lepto. pdf.> Acesso em: 8 abr. 2008.

GUIMARÃES, M. C.; CÔRTES, J. A.; VASCONCELLOS, S. A.; ITO, F. H. Epidemiologia e controle da leptospirose em bovinos: papel do portador e o seu controle terapêutico. Comunicação Científica da Faculdade de Medicina Veterinária e Zootecnia da USP, v. 6-7, n. 1-4, p. 21-34, 1982-1983.

IBGE Pecuária 2006. [online] Disponível em: <http://www.ibge. gov.br/estadosat/temas.php?sigla $=$ go\&tema $=$ pecuaria2006\&titulo $=$ Pecu\%E1ria\%202006. $>$ Acesso em: 19 maio 2008 .

JARDIM, E. C. Aglutininas anti-leptospira em bovinos do Estado de Goiás. Anais das Escolas de Agronomia e Veterinária da UFG, n. 1, p. 188, 1978.

JULIANO, R. S. Estudo da prevalência e aspectos epizootiológicos da leptospirose bovina, no bebanho de fêmeas mestiças produtoras de leite na microregião de Goiânia, GO. 1999. 60 
f. Dissertação (Mestrado em Sanidade Animal) - Escola de Veterinária, Universidade Federal de Goiás, Goiânia.

KIRKBRIDE, C. A. Laboratory Diagnosis of Livestock abortion. 3. ed. Ames: State University Press, 1990. p. 59-65.

LAGE, A. P.; LEITE, M. H.; THOMPSON, J. A.; BANDEIRA, D. A.; HERRMANN, G. P.; MOREIRA, E. C.; GONÇALVES, V. S. P. Serology for Leptospira sp. in cattle of the state of Paraíba, Brazil. Arquivos do Instituto Biológico, v. 74, n. 3 , p. 185-190, jul.-set. 2007.

LANGENEGGER, J. Aborto causado por leptospiras: diagnóstico e medidas de controle da leptospirose em bovinos. Pesquisa Veterinária Brasileira, v. 10, n. 1-2, p. 4-5, 1990.

LANGONI, H.; MARINHO, M.; BALDINI, S.; SILVA, A. V.; CABRAL, K. G.; SILVA, E. R. Pesquisa de aglutininas antileptospíricas em soros de ovinos no Estado de São Paulo, Brasil, utilizando provas de macroaglutinação em placa e soroaglutinação microscópica. Revista Brasileira de Medicina Veterinária, v. 17, n. 6, p. 264-268, 1995.

LANGONI, H.; MEIRELES, L. R.; GOTTSCHALK, S.; CABRAL, K. G.; SILVA, A. V. Perfil sorológico da leptospirose bovina em regiões do Estado de São Paulo [online], 2001. Disponível em: $<$ http://www.biologico.sp.gov.br/docs/arq/V67_1/perfil_sorologico.html.> Acesso em: 8 abr. 2008.

LILENBAUM, W. Atualização em leptospiroses bovinas. Revista Brasileira de Medicina Veterinária, v. 18, n. 1, p. 9-13, 1996.

LILENBAUM, W.; SANTOS, M. R. C. Leptospirose em reprodução animal: III - Papel do serovar hardjo nas leptospiroses bovinas no Rio de Janeiro. Revista Brasileira de Ciências Veterinárias, v. 2, n.1, p. 1-6, 1995.

LINHARES, G. F. C.; GÍRIO, R. J. S.; LINHARES, D. C. L.; MONDEIRO, L. C.; OLIVEIRA, A. P. A. Sorovares de Leptospira interrogans e respectivas prevalências em cavalos da microrregião de Goiânia, GO. Ciência Animal Brasileira, Goiânia, v. 6, n. 4, p. 255-259, out.-dez. 2005.

MAGAJEVSKI, F. S.; GÍRIO, R. J. S.; MEIRELLES, R. B. Pesquisa de Leptospira em fetos de vacas abatidas no estado de São Paulo, Brasil. Arquivos do Instituto Biológico, v. 74, n. 2, p. 67-72, abr.-jun. 2007.

MILLER, M. A.; TURK, J. R. Causas infecciosas de infertilidade e de aborto In: SMITH, B. P. Tratado de medicina interna de grandes animais. São Paulo: Manole, 1994. p. 1399.
MINEIRO, A. L. B. B. Aglutininas anti-Leptospira em bovinos leiteiros da microrregião de Parnaíba, Piauí: associação com histórico de transtorno reprodutivo e condições climáticas. 2003. 72 f. Dissertação (Mestrado em Ciência Animal) - Centro de Ciências Agrárias, Universidade Federal do Piauí, Teresina, 2003.

OIE. Manual of standars for diagnostics tests and vaccines. Paris: OIE, 1992.

PFIZER. Vacinação contra rinotraqueíte infecciosa bovina (IBR), diarréia viral bovina (BVD) e leptospirose. Atualização técnica Laboratórios Pfizer Ltda., n. 50, p. 1-6, 2000.

PRESCOTT, J. F.; MILLER, R. B.; NICHOLSON, V. M.; MARTIN, S. W.; LESNICK, T.Seroprevalence and Association with abortion of leptospirosis in cattle in Ontário. Canadian Journal of Veterinary Research, n. 52, p. 210-215, abr. 1988.

ROCHA, W. V. Soroprevalência, distribuição regional e fatores de risco da brucelose em fêmeas bovinas adultas no Estado de Goiás. 2003. 63 f. Dissertação (Mestrado em Sanidade Animal) - Escola de Veterinária, Universidade Federal de Goiás, Goiânia, 2003.

RODRIGUES, A. M. A.; VASCONCELLOS, S. A.; MORAES, Z. M.; HAGIWARA, M. K. Isolamento de Leptospira spp. de cães com diagnóstico clínico de leptospirose em São Paulo (Brasil). Acta Scientiae Veterinariae, v. 35, p. 705-706, 2007.

RODRIGUES, C. G.; MÜLLER, E. E.; FREITAS, J. C. Leptospirose bovina: sorologia na bacia leiteira da região de Londrina, Paraná, Brasil. Ciência Rural, v. 29, n. 2, p. 309-314, 1999.

SCHULZE, C. M. B. Prevalência de anticorpos anti-Neospora caninum em fêmeas bovinas do Estado de Goiás e fatores associados. 2008. 65 f. Dissertação (Mestrado em Sanidade Animal) - Escola de Veterinária, Universidade Federal de Goiás, Goiânia, 2008.

SHIMABUKURO, F. H.; DOMINGUES, P. F.; LANGONI, H.; SILVA, A. V.; PINHEIRO, J. P.; PADOVANI, C. A. Pesquisa de suínos portadores renais de leptospiras pelo isolamento microbiano e reação em cadeia pela polimerase em amostras de rins de animais sorologicamente positivos e negativos para leptospirose. Brazilian Journal of Veterinary Research and Animal Science, v. 40, p. 243-253, 2003

TRHUSFIELD, M. V. Epidemiologia veterinária. São Paulo: Roca, 2004. 556 p.

VASCONCELLOS, S. A. Leptospirose bovina: atualização técnica. Laboratórios Pfizer, n. 34, p. 1-5, 1997. 